\title{
FLASHES INTERMITENTES: \\ A PRESENÇA DA FOTOGRAFIA EM DOM CASMURRO
}

\author{
Cintia Kozonoi Vezzani \\ Universidade de São Paulo \\ São Paulo (SP), Brasil
}

\begin{abstract}
Resumo: O presente artigo parte do tema da fotografia para valer-se dele como modo de compreensão do narrador em Dom Casmurro, romance publicado por Machado de Assis em 1899. Através do levantamento de passagens do enredo centradas em algum retrato (englobando nessa categoria pinturas e fotografias), desenvolve-se a noção de "narração-fotográfica", que visa enfatizar a reiteração de hipóteses e rememorações realizadas pela personagem Bentinho a partir de instantes cristalizados no tempo. A necessidade de posse através do apego às imagens, assim como aos momentos vividos relembrados pela memória, destaca a luta interior da personagem contra o esquecimento de momentos, a solidão e a condição efêmera da vida.
\end{abstract}

Palavras-chave: Dom Casmurro; fotografia; narração; memória; esquecimento.

\section{Intermittent flashes: the presence of photography in Dom Casmurro}

\begin{abstract}
The starting point of this article is the theme of photography as a way of understanding the narrator in Dom Casmurro, a novel published by Machado de Assis 1899. By selecting important scenes centred on the image of a portrait (including paintings and photographs), the article develops the notion of "photographicnarration", which aims to emphasize the reiteration of hypotheses and of things remembered by the character Bentinho, referring to moments crystallized in time. The need of possession by creating an attachment to the images, as well as to moments relived through memory, highlights the character's inner struggle against forgetfulness, loneliness and life's ephemeral condition.
\end{abstract}

Keywords: Dom Casmurro; photography; narration; memory; forgetfulness.

"Agora lembrava-me tudo o que então me pareceu nada." 
Dom Casmurro, Capítulo CXL - "Volta da igreja"1

O presente artigo tem como objetivo refletir sobre a complexidade e a importância do olhar no romance Dom Casmurro, a partir de dois eixos principais: a relevância da fotografia enquanto espaço para fixação do tempo, resultando em um objeto de obsessão no romance; e o valor de "ver e ser visto" no quadro social da época, através da fotografia. Aproveitando o título do ensaio de Alfredo Bosi, "O enigma do olhar", pode-se meditar sobre o quanto a palavra "enigma" ressalta a questão misteriosa e indecifrável desse olhar sempre móvel, atento, dinâmico, que ora se aproxima e ora se distancia do objeto mirado. Mas, acima de tudo, a questão do olhar é central para entender as transformações pelas quais o século XIX passou, como a expansão da imprensa, o aumento da velocidade das informações, os veículos de massa que precisavam atrair os seus leitores com o uso da publicidade e a divulgação de tendências da moda, estabelecendo regras que definiam a aceitabilidade dentro de um mundo regido pelas aparências.

A necessidade de ser visto, reconhecido, de ser "grande e ilustre" como nos afirma o pai em diálogo (quase monólogo) com o seu filho, no conto "Teoria do medalhão", enfatiza o papel essencial da mídia: "Uma notícia traz outra; cinco, dez, vinte vezes põe o teu nome ante os olhos do mundo." ${ }^{2}$ Embora isso revele a importância numérica voltada para um "crescendo" midiático que estima a quantidade e não propriamente o conteúdo veiculado, tal passagem sublinha uma segunda condição dessa nova era imagética: a sua efemeridade. A necessidade da constante divulgação do "nome" está ligada ao fato de que a notícia, publicada uma vez, no dia seguinte já será esquecida, precisando assim de uma nova publicação, "cinco, dez, vinte vezes", e, quanto mais vezes, mais sólida a expansão vai acontecendo, auxiliando no prolongamento desse temporário brilho.

Outra possibilidade de registro que contribui para a fixação desses instantes passageiros é a fotografia. Enquanto apreensão de rostos ou paisagem, ela funciona ao

\footnotetext{
1 Todas as menções aos textos de Machado de Assis têm como referência o site: <http://machado.mec.gov.br>

2 ASSIS, Machado. Teoria do medalhão. In: <http://machado.mec.gov.br/images/stories/html/ contos/macn003.htm>. Texto fonte: ASSIS, Machado. Obra Completa, v. 2. Rio de Janeiro: Nova Aguilar, 1994.
} 
lado da pintura, sendo que esta última é arte remota que não tem o seu valor diminuído na sociedade pictórica, mas que perde seu espaço por uma questão prática: o tempo. A novidade, como expressada no Jornal do Commercio, enfatiza o quanto era

preciso ter visto a cousa com os seus proprios olhos para se poder fazer idéa da rapidez e do resultado da operação. Em menos de nove minutos o chafariz do largo do Paço [...] se acharão reproduzidos com tal fidelidade, precisão e minuciosidade. ${ }^{3}$

Nesse mundo no qual o tempo parece se esvair, é vantajoso encontrar sempre novos meios que permitam o seu melhor aproveitamento dentro do ritmo acelerado da vida. E é extremamente curioso o tríplice ponto de partida para a teoria do crítico alemão Thomas Sträter em seu ensaio "Fotografia do invisível": a coincidente data entre o nascimento da técnica da reprodução da fotografia e o nascimento do escritor brasileiro Machado de Assis: o ano de 1839. Número que foi notado por Sträter como aquele que dá título ao capítulo "Fotografia" em Dom Casmurro: CXXXIX (139). ${ }^{4}$

Sträter afirma que "no momento em que o olho é capaz de fotografar, a percepção é necessariamente determinada pela fotografia", e tal possibilidade de leitura auxilia no acompanhamento do movimento do olhar do narrador de Dom Casmurro. O romance, além de conter um título que explicita a importância da fotografia em seu enredo (o já mencionado capítulo CXXXIX), é também contemporâneo à popularização da fotografia promovida pela marca Kodak em 1888 (o romance é publicado dez anos depois, em 1899, portanto ainda respirando o ar dessa novidade que estava cada vez mais sendo manipulada e desenvolvida). O tema e o olhar fotográfico se unem para narrar o descontrolado anseio por reproduzir, relembrar e reviver o passado em busca de um sentido até então incompreendido. O primeiro exemplo concreto dessa ambição é a idêntica reconstrução da casa no Engenho Novo, sendo a cópia da "casa em que me criei na antiga rua de Matacavalos, dando-lhe o mesmo aspecto e economia daquela outra,

\footnotetext{
317 de Janeiro de 1840, Jornal do Commercio. cit. STRÄTER, Thomas. "Fotografia do Invisível. A invenção de Daguerre na obra de Machado de Assis" in. MINISTÉRIO DAS RELAÇÕES EXTERIORES / GOVERNO FEDERAL. $1^{\circ}$ Concurso Internacional Machado de Assis - ensaios premiados - a obra de Machado de Assis. Brasília: Ed. Bandeirantes, 2006. p. 193.

${ }^{4}$ Idem, p. 196 (meus grifos).
} 
que desapareceu." Talvez se possa dizer que a luta central do romance seja essa constante ambição pela apreensão do ofuscado, ou seja, aquilo que não pode ser totalmente apagado, mas que habita a nuance entre o claro e o escuro. Tamanha é a necessidade da sua completa rememoração, que nos parece que o narrador gira ao seu próprio redor, fotografando cenas vazias, colorindo-as e iluminando-as com o flash da câmera, a partir do presente da enunciação que realiza uma motivada leitura da sua memória, graças à escritura das mesmas.

A apresentação da mãe do narrador, D. Glória, no sétimo capítulo do romance, tem como alicerce o "retrato dela, ao lado do marido". Entendemos a concepção de retrato como sendo um termo que engloba tanto o registro fotográfico quanto a pintura, salientando a ausência de um julgamento de valores entre ambas as artes/técnicas, vistas como manifestações histórico-sociais distintas que têm, por sua vez, características que permitem essa aproximação de esferas visando uma representação. ${ }^{5}$ No requisito das técnicas, incluem-se a questão da própria duração e a alteração do material em sua concretude. A pintura de seus pais, segundo o narrador, "escureceu muito", mostrando que até mesmo ela, objeto da permanência, não escapa das marcas que o tempo, quando passa, deixa em nós. Até ela escureceu, até nela, imagem congelada, algo foi alterado em relação ao momento em que foi fixada. Por mais que tal sutileza pareça não precisar ser salientada, ela serve como metonímia ao próprio ato de narração realizada por essa voz, que narra a partir do presente da enunciação e que olha para o tempo do vivido já manchado pela distância temporal. É como se esse narrador se juntasse à fala de Boileau: "Apressemo-nos: o tempo foge e nos arrasta consigo; o momento em que falo já vai longe de mim."

\footnotetext{
${ }^{5} \mathrm{O}$ tema da relação entre fotografia e pintura na vida do escritor encontra-se mencionado no livro $A$ olhos vistos: uma iconografia de Machado de Assis, na legenda de uma "Fotografia tirada quando Machado posava para o pintor Henrique Bernadelli, em 1905. Na pintura aparece o ramo do carvalho de Tasso, que não está na fotografia." (GUIMARÃES, Hélio de Seixas e SACCHETTA, Vladimir. Org. A olhos vistos: uma iconografia de Machado de Assis. São Paulo: Instituto Moreira Salles, 2008. p. 143). A possibilidade de posar para uma pintura e ser ao mesmo tempo fotografado enfatiza a aproximação entre as duas formas de representação, que nesse instante praticamente convergem para a mesma cena, no mesmo momento. A diferença, além do detalhe inserido na pintura que permite essa modificação do real, está na duração do seu processo.

${ }^{6}$ BOILEAU, Antoine. O enigma do tempo. In: ASSOCIAÇÃO BRASIL SGI. Revista Terceira Civilização. São Paulo: Ed. Brasil Seikyo, 1993. p. 20-27.
} 
Relutante face ao "encardido do tempo", o narrador se apropria do conectivo adversativo "mas" para mostrar a convicção de que o retrato "ainda dá ideia de ambos". Esse presente do "dar" revela não uma rememoração do que foram, mas a imagem que queriam deixar. É a descrição da pintura mesclada às lembranças que permite que comecemos a delinear o próprio "eu" desse Dom Casmurro. Ele declara que os olhos de seu pai o "acompanham para todos os lados" e justifica tal implicação como sendo "efeito de pintura". Que efeito é esse, quais as técnicas artísticas externas que auxiliam nesse traço de criança amedrontada pelos olhos de um pai ausente, mas presente por meio do retrato que o representa? O Bentinho de então vai se formando pela observação de um retrato, cuja leitura continua explicitada pelo verbo "ler" ("o que se lê na cara de ambos"). A contemplação do retrato torna-se objeto de análise para o narrador. Assim, como um objeto inanimado que permanece em silêncio face ao seu observador, a fotografia se emudece, enquanto aquele que a vê livremente estabelece hipóteses nascidas da sua própria interpretação de uma possível expressão, passando a dizer que ela "parecia oferecer" algo que não está concretamente na sua imagem.

Trata-se do seguinte circuito: sair de um resultado concreto (a foto), passar pelo clive interno do narrador e chegar a uma certeza a respeito de outrem: eles, os retratados, eram conectados pela "felicidade conjugal". A afirmação é baseada em uma pintura: a parte levada ao todo, a parte conectando-o com ele mesmo no âmbito familiar (que ele quer, espera que assim tenha sido). A possibilidade de uma leitura fotográfica será reaproveitada na visão de seu amigo seminarista, Escobar, no capítulo LXXI ("Visita de Escobar"), ao olhar o retrato do pai: "- Vê-se que era um coração puro". Sträter justifica o título do seu ensaio ("Fotografia do invisível") como sendo uma teoria formulada pelo próprio Machado, pioneiro da "fotografia literária", em que revela o "invisível do interior". Tanto Escobar como Bentinho, pela visão e pela leitura, conseguem "radiografar" sentimentos e sensações que vão além da tinta sobre a tela, da luz sobre o papel.

Retornando ao capítulo VII, mais especificamente, no retrato dos pais de Bentinho, identifica-se outra característica desse narrador na afirmação: "aqui os tenho" (os retratos). Tal declaração gera uma possível sensação de que possuir uma foto é dominar momentos e até pessoas, permitindo e servindo, ao mesmo tempo, como encobrimento daquilo que está, na verdade, ausente. Por esse viés, as concepções de 
verdade e realidade se fragilizam, já que existem meios que disfarçam e preenchem o vazio dos que não estão (retratos), nos lugares em que não estamos (reconstrução da casa), vivendo um passado impossibilitado de ser revivido (com exceção da escrita, que visa essa rememoração). Na afirmação de que "são retratos que valem por originais" é visível a conexão dessa construção com a do capítulo "Aceito a teoria" (X): a "verossimilhança, que é muita vez a verdade". Nesse instante, a verdade e o original são postos em cheque, ao serem igualados ou indiferenciados face às cópias, ao verossímil, ao reproduzível.

A própria conclusão do capítulo VII reforça esse posicionamento de que a possibilidade tem um valor mais elevado do que o fato em si (ou a ausência dele). Ao dizer que seus retratos são "como fotografias instantâneas da felicidade", o uso do "como" implica que a afirmação não é uma verdade, mas é como se fosse, e isso é suficiente para satisfazer o narrador, fruto dessa relação. Adiantando uma frase que aparece apenas posteriormente no romance ("Os autos", cap. CXX), "naquele tempo a minha vista era boa": ela nos reforça a condição do olhar, da vista deturpada, da vista que vê o que quer, o que, segundo o "óculos da memória", quer enxergar.

Retomando o andamento linear do romance, um próximo momento no qual a questão do retrato é central para a configuração das personagens encontra-se no final do capítulo L, "Um meio-termo", momentos antes da ida de Bentinho ao seminário. No final do último parágrafo, o narrador relata o pedido de Capitu para que recebesse uma fotografia da mãe de Bento, que pela primeira vez a chamara de "filha". Em Machado, nenhuma descrição é por acaso ou meramente gratuita. Pelo contrário, tal passagem que liga Capitu a D. Glória começa com uma negação do pedido inicial (ser fotografada), seguida de uma hesitação, com o oferecimento de uma miniatura que a retrata jovialmente. A reação de Capitu, por sua vez, é "indescritível", segundo o narrador. Se seguirmos a teoria da inclinação da moça pela ascensão social através do casamento com o Bentinho, não nos espantamos com a "paixão" dela pela foto da jovem D. Glória. Isso se evidencia na descrição da felicidade de Capitu ao finalmente divulgar a sua "alegria [...], o ar de casada [...] tudo me mostrou que a causa da impaciência de Capitu eram os sinais exteriores do novo estado." (cap. CII - "De casada"). 
D. Glória faz questão de entregar apenas um retrato que marcasse o auge da sua mocidade (25 anos), acentuando a sua preocupação com a imagem física. Opta pelo corpo ainda jovem e belo, antes de ser tocado pela passagem do tempo, assim como as cicatrizes das vivências, incluindo as mudanças de hábito (sempre vestida de preto), fruto da viuvez. Por meio da escolha da fotografia, D. Glória evoca o seu passado "áureo", negando o seu descolorido presente, além de dialogar diretamente com a posição de moça que Capitu ocupa e que ela mesma ocupara, outrora, servindo quase como um bastão de continuidade de papéis que serão preenchidos durante esse rápido tempo. Ela, que já tivera 25 anos, hoje esconde seu corpo em panos escuros, e Capitu, tão "Capitu", não escapará desse processo, assim como o próprio retrato dos pais de Bentinho, que escureceram com o tempo.

Entretanto, o apego da jovem à foto não é exclusivamente resultado do conteúdo da imagem retratada, por ser esta ninguém menos que D. Glória, figura dotada de um status social elevado, mãe e dona do lar a que ela imagina que um dia pertencerá; mas a sua afeição é inclusive pelo objeto em si: uma miniatura que aqui se aproxima com a "carte de visite", prática social da época de Machado de Assis. Conforme explicado no ensaio "A composição de uma figura - anotações sobre as fotografias de Machado de Assis" por Hélio Guimarães,

[...] esses retratos, montados em forma de cartões, eram item obrigatório da sociabilidade chique daquela altura do século XIX. Costumavam ser trocados entre homens e mulheres bem colocados na hierarquia social ou em busca de ascensão social. ${ }^{7}$

Os olhos de Capitu para a miniatura de D. Glória "não eram oblíquos, nem de ressaca, eram diretos, claros, lúcidos." ${ }^{8}$ Nas mãos da menina estava o material requisitado desse círculo elevado que, segundo as opiniões iniciais do agregado José

\footnotetext{
${ }^{7}$ GUIMARÃES, Hélio. A composição de uma figura - anotações sobre as fotografias de Machado de Assis. In: ___ _ SACCHETTA, Vladimir (Orgs.). A olhos vistos: uma iconografia de Machado de Assis. São Paulo: Instituto Moreira Salles, 2008. p. 9.

${ }^{8}$ ASSIS, Machado. Dom Casmurro. In:

$<$ http://machado.mec.gov.br/images/stories/html/romance/marm08.htm >. Texto fonte: Obras Completas de Machado de Assis, v. 1. Rio de Janeiro: Nova Aguilar, 1994. Capítulo L ("Um meio termo"). Grifos meus.
} 
Dias e da Prima Justina, era o status visado por Capitu. O próprio narrador enfatiza a sua sede de exibição, ao compreender a origem da impaciência de Capitu para voltar logo para casa depois do casamento como "sinais exteriores do novo estado. Não lhe bastava ser casada entre quatro paredes e algumas árvores; precisava do resto do mundo também." (cap. CII)

$\mathrm{O}$ resto do mundo tem as suas portas abertas pela chave da carte de visite, objeto, imaginemos, tão desejado pela "gente do Pádua", que merece, por sua vez, um olhar mais aprofundado, pois não deixa de ser um objeto problemático dentro do universo machadiano. Ao folhear o livro A olhos vistos: uma iconografia de Machado de Assis, é visível o predomínio da carte de visite: "fotografia copiada sobre papel albuminado e colado sobre um suporte de papel mais grosso, de aproximadamente 10,5 x 6,3cm". ${ }^{9}$ Machado reuniu, junto com sua esposa Carolina, um vasto conjunto de fotos que, se não fosse a passagem do tempo, mal poderíamos notar a diferença de uma para a outra, uma vez que a posição fixa e o enquadramento já delimitado transformam o ser fotografado em objeto quase inanimado frente às lentes dos fotógrafos especializados nesse tipo de retrato, como o destacado Joaquim Insley Pacheco, que tinha, "entre seus clientes 'pessoas da mais alta sociedade'". ${ }^{10}$ Guimarães ainda detalha que essas cartes "eram o retrato burguês por excelência, e, calcula-se, correspondiam a $90 \%$ das fotografias produzidas na segunda metade do século XIX, sempre em composições muito parecidas e redundantes."11

Ao retomarmos os conselhos dados pelo pai para que o seu filho se torne um brilhante Medalhão, ${ }^{12}$ veremos que ele sustenta: "E depois não obriga a pensar e descobrir. Nesse ramo dos conhecimentos humanos tudo está achado, formulado, rotulado, encaixotado." Já em uma crônica do escritor de 7 de Agosto de 1864, o escritor observa: "Desde então para cá, isto é, no espaço de vinte quatro anos, a máquina

\footnotetext{
${ }^{9}$ GUIMARÃES, Hélio. Apresentação. In: iconografia de Machado de Assis, cit., p. 3. ; SACCHETTA, Vladimir (Orgs). A olhos vistos: uma

${ }^{10}$ GUIMARÃES, Hélio. A composição de uma figura - anotações sobre as fotografias de Machado de Assis". In: ; SACCHETTA, Vladimir (Orgs). A olhos vistos: uma iconografia de Machado de Assis, cit., p. 9.

${ }^{11}$ Idem. p. 4.

12 ASSIS, Machado. "Teoria do medalhão". In: <http://machado.mec.gov.br/images/stories/html/ contos/macn003.htm>. Texto fonte: ASSIS, Machado. Obra Completa, v. 2. Rio de Janeiro: Nova Aguilar, 1994.
} 
do padre Combes produziu as trinta casas que hoje se contam na capital, destinadas a reproduzir as feições de todos quantos quiserem passar à posteridade... num bilhete de visita." ${ }^{13}$ Como em um quebra-cabeças, temos diferentes manifestações, ou melhor, diferentes ângulos fotográficos a respeito do mesmo tema: por um lado, a personagem Capitu, que domina o objeto, chegando a beijá-lo, revelando que o seu significado ia muito além de um mero retrato, pois representava um pacto entre duas mulheres de classes distintas. Por outro, um pai que incentiva o filho a seguir exatamente o modelo já preestabelecido, sem refletir, questionar ou alterar nada. E, por fim, Machado, ele mesmo visitando o estúdio de Pacheco e comentando o processo fotográfico de uma forma que mescla a posteridade com a banalidade. E não podemos esquecer o papel manifestado por Machado dentro dessa prática social necessária. Aquilo que pode ser lido como um conselho verdadeiro de um pai preocupado com seu filho parece ser ironizado na crônica, mas é uma vez recebido apaixonadamente por Capitu, e Machado não deixava de atualizar periodicamente o seu próprio "bilhete de visita".

Como Guimarães ressalta,

[...] pouco sabemos sobre o modo de circulação desses objetos [...] que costumavam ser trocados entre amigos, parentes e amantes. Mas sabemos que essas imagens circulavam e que o escritor estava longe de ser indiferente a elas. ${ }^{14}$

Há, sem dúvida, uma intensa preocupação pela imagem, que não se limita ao presente, mas principalmente ao futuro, ao olhar da posteridade: "não é bonito aparecer despenteado aos olhos do futuro", revelou Machado em "A semana" (1895). Não apenas no âmbito físico deve-se seguir uma estrita ordem, mas também no modo de se portar, nas feições, no eterno "estar bem'", positivo, sorridente ou então sério, independentemente do momento. No romance, o narrador enfatiza essa compostura moral e social refletida no físico, ao alegar que "as lágrimas, se as têm, são enxugadas

\footnotetext{
13 ASSIS, Machado. 7 de Agosto de 1864. Ao acaso: crônicas 1864-1865. In: <http://machado.mec.gov.br/images/stories/html/cronica/macr04.htm>. Publicado originalmente no Diário do Rio de Janeiro, Rio de Janeiro, de 12/06/1864 a 16/05/1865.

${ }^{14}$ GUIMARÃES, Hélio. A composição de uma figura - anotações sobre as fotografias de Machado de Assis". In: ; SACCHETTA, Vladimir (Orgs). A olhos vistos: uma iconografia de Machado de Assis, cit., p. 11.
} 
atrás da porta, para que as caras apareçam limpas e serenas; os discursos são antes de alegria que de melancolia" ("Uma comparação", cap. CXXV). A própria descrição de Capitu ao se olhar no espelho: "concertou os cabelos tão demoradamente que parecia afetação, se não soubéssemos que ela era muito amiga de si" (cap. CXXVIII), mesmo na densa atmosfera do falecimento de Escobar, aponta a extrema preocupação do ser exterior. A aparência deve ser superior aos eventos em si, e as pessoas passam a se portar como estátuas: frias, expressões premeditadas. No capítulo CXI, "As imitações de Ezequiel", o narrador busca a matéria-prima no próprio mármore, o congelamento do instante do abraço e de um "riso doce [...] desses risos que não se descrevem, e apenas se pintarão."

Interessante notar, mas não visando repetir a questão nomeada por Sträter em "A fotografia como motivo determinante: Dom Casmurro", que é ela, a fotografia, que "vai ter a função crucial de ser para Bentinho a última e decisiva prova da (suposta) traição por sua mulher Capitu com o amigo Escobar." Entretanto, mais do que destacar as passagens da fotografia como força motriz para a execução de escolhas e visões de mundo, como o caso do retrato de Escobar para Bento nos capítulos "A mão de Sancha" (cap. CXVIII), "A xícara de café" (cap. CXXXVI) e "A fotografia" (cap. CXXXIX), julgamos que o capítulo CXLV, "O regresso" merece atenção especial. Este guarda em si o desfecho que na verdade concretiza, em certo sentido, o "fim evidente" do livro: "atar as duas pontas da vida, e restaurar na velhice a adolescência" (cap. II).

Embora o narrador diga que não conseguiu "recompor o que foi nem o que fui", através do escopo da fotografia fica evidente não só a conexão entre as pontas da sua vida, mas sobretudo entre a reprodução da sua vida na infância com relação ao pai e ele enquanto pai se relacionando com o filho. Se a presença do pai foi, para ele, preenchida através do retrato dele (pai) ao lado de D. Glória, Ezequiel, por sua vez, também cresceu sem a presença física do pai, mas acompanhado de seus retratos: "conhece-me pelos retratos e correu para mim." D. Glória, sozinha, foi quem deu a solitária miniatura para Capitu, que acabou isolada com o filho na Suíça, repetindo o caminho que a foto inicial já indicara: uma ânsia por um reencontro, um louvor extraordinário, vontades frustradas e enterradas com seus corpos. Se, para Bentinho, eram os olhos do pai que o assombravam como "efeito de pintura", o reencontro entre Ezequiel e seu pai é marcado pela observação da pintura agora externa a eles: do busto 
de Massinissa. Segundo a história, o filho de Massinissa, Jugurta, escolhe combater aquela que foi aliada do seu próprio pai: Roma. Este acaba sendo derrotado. No fim da união das pontas das vidas, no sentido de reproduções, as cópias acabam tendo o mesmo fim que os originais: uma vida fragmentada e vazia.

Para concluir este recorte sobre a relação entre fotografia e pintura em Machado, especificamente a sua presença no romance Dom Casmurro, ressaltamos a abertura do capítulo LI: "Entre a luz e fusco, tudo há de ser breve como esse instante." Não deixa de ser curioso como Machado sofisticadamente aproveita termos, ou ao menos realidades físicas, do universo fotográfico para sua própria narração (a relação entre a luz e o fusco, a luz clareando pelo flash a escuridão real). A fotografia, cujo mecanismo foi bem explicado por Sträter, começa pelo daguerreotipo, que

[...] tratava-se ainda de uma imagem única e positiva, diretamente formada em uma placa metálica normalmente de cobre e revestida por uma camada de prata cuidadosamente sensibilizada por vapores de iodo, que the conferem um tom levemente dourado [...] O resultado era uma imagem prateada-metálica espelhando-se em diferentes nuances, de um encanto ímpar e que uma reprodução em papel nunca pode alcançar. Dependendo do ângulo de vista, pode aparecer como negativo ou positivo $[\ldots]^{15}$

até chegar na invenção propriamente do processo negativo que culminaria na capacidade de "reproduzir a imagem em cópias em número ilimitado."

Ainda nesse capítulo LI, e voltando à nossa leitura para a forma da narração, a acusação do narrador ao leitor ("e a malícia está antes na tua cabeça perversa que na daquele casal de adolescentes") parece um comentário de uma foto: é a própria maneira de narrar, na qual o ato do beijo reside na descrição de uma "conjunção das nossas bocas amorosas" sem reviver narrativamente a ação em si, uma vez que o movimento geraria uma cena cinematográfica. Somos posicionados ao lado do narrador, que segura em suas mãos o retrato que mostra dois rostos selados congeladamente por um beijo. Em seguida, o tom saudoso de "Oh! minha doce companheira da meninice [...]" permite

${ }^{15}$ STRÄTER, Thomas. Fotografia do invisível: a invenção de Daguerre na obra de Machado de Assis. In: MINISTÉRIO DAS RELAÇÕES EXTERIORES / GOVERNO FEDERAL. $1^{\circ}$ Concurso Internacional Machado de Assis - ensaios premiados - a obra de Machado de Assis. Brasília: Bandeirantes, 2006. p. 192. 
até a visualização desse narrador falando com a foto, dialogando com as memórias que revive, falando com aquilo que não poderá lhe responder: "mas a vocação eras tu, a investidura eras tu." A resposta da fala é o silêncio da foto e a imagem estática de um beijo pontual, efêmero, terminado, passado.

Mas é justamente essa "narração-fotográfica" que vai de encontro à declaração de que "esquecer, qualquer esquece" (cap. CXIV), mas graças ao congelamento da prosa e à análise miúda e fria de fotografias e pinturas, o que era para ser esquecido não o é. O narrador, extremamente consciente do seu domínio sobre a narrativa, realça, em outra passagem, o seu poder de construção ficcional: "[...] até que a família pendura o quadro na parede, em memória do que foi e já não pode ser. Aqui podia ser e era." (Cap. CXXXII) O "Aqui", no romance, se trata da narração formada por curtíssimos e concentrados capítulos que olhados como um todo parecem formar um álbum fotográfico, sendo constantes as fotos nas quais ele está, na verdade, analisando um outro retrato. E é nesse mergulho de retratos em retratos, flashes que clareiam memórias e apagam (ou cegam) outras, que o narrador parece nadar contra o fluxo natural do esquecimento, aflorando uma intensa necessidade do registro que eternize, que capte cada vez mais rapidamente os instantes mais efêmeros, cujo valor reside nessa superficialidade do mundo das aparências, um mundo vazio.

Referências:

ASSIS, Machado. Dom Casmurro. In: <http://machado.mec.gov.br/images/stories/ $\mathrm{html} /$ romance/marm08.htm >. Texto fonte: . Obras Completas de Machado de Assis, v. 1. Rio de Janeiro: Nova Aguilar, 1994.

Teoria do medalhão. In: <http://machado.mec.gov.br/images/stories/html/ contos/macn003.htm>. Texto fonte: . Obra Completa, v. 2. Rio de Janeiro: Nova Aguilar, 1994. 
7 de Agosto de 1864. Ao acaso: crônicas 1864-1865. In: <http://machado.mec.gov.br/images/stories/html/cronica/macr04.htm>. Publicado originalmente no Diário do Rio de Janeiro, Rio de Janeiro, de 12/06/1864 a 16/05/1865.

BOILEAU, Antoine. O enigma do tempo. In: ASSOCIAÇÃO BRASIL SGI. Revista Terceira Civilização. São Paulo: Ed. Brasil Seikyo, 1993. p. 20-27.

GUIMARÃES, Hélio. Apresentação. In: ; SACCHETTA, Vladimir (Orgs). A olhos vistos: uma iconografia de Machado de Assis. São Paulo: Instituto Moreira Salles, 2008 .

A composição de uma figura - anotações sobre as fotografias de Machado de Assis. In: _ _ SACCHETTA, Vladimir (Orgs.). A olhos vistos: uma iconografia de Machado de Assis. São Paulo: Instituto Moreira Salles, 2008.

STRÄTER, Thomas. "Fotografia do Invisível. A invenção de Daguerre na obra de Machado de Assis" in. MINISTÉRIO DAS RELAÇÕES EXTERIORES / GOVERNO FEDERAL. $1^{\circ}$ Concurso Internacional Machado de Assis - ensaios premiados - a obra de Machado de Assis. Brasília: Ed. Bandeirantes, 2006.

Cintia Kozonoi Vezzani é estudante de graduação do curso de Letras, com dupla habilitação, em Português e em Francês, na Universidade de São Paulo e bolsista de Iniciação Científica (RUSP) no projeto A narrativa da ficção em Fernando Pessoa. Email: <cintia.vezzani@gmail.com>

Recebido: $14 / 09 / 2012$

Aprovado: 19/11/2012 